\title{
Valvular Stenosis
}

National Cancer Institute

\section{Source}

National Cancer Institute. Valvular Stenosis. NCI Thesaurus. Code C62433.

Narrowing of the opening of one or more of the four valves of the heart. 